El Derecho Internacional Privado Colombiano ante la Ley Modelo OHADAC de DIPr

Patricia Orejudo Prieto de los Mozos*

Publicado en Anuario Español de Derecho internacional privado, t. XIII, 2013, pp. 681-697

* Profesora Titular de Derecho internacional privado

Facultad de Derecho

Universidad Complutense de Madrid

patricia.orejudo@der.ucm.es

Trabajo depositado en el archivo institucional E-Prints Complutense http://eprints.ucm.es 


\title{
EL DERECHO INTERNACIONAL PRIVADO COLOMBIANO ANTE LA LEY MODELO OHADAC DE DIPR
}

\author{
Patricia OREJUDO PRIETO DE LOS MOZOS \\ Profesora titular de Derecho internacional privado \\ Universidad Complutense de Madrid
}

\begin{abstract}
SUMARIO: I. Introducción. II. Carácter incompleto y disperso del actual Derecho internacional privado: 1. Competencia judicial internacional: A) Regulación estatal. B) Convenios internacionales. 2. Determinación de la ley aplicable: A) Regulación estatal; B) Convenios internacionales. 3. Reconocimiento y ejecución de decisiones extranjeras: A) Regulación estatal. B) Convenios internacionales. 4. Cooperación internacional entre autoridades. III. El limitado papel de la jurisprudencia. IV. Conclusiones.
\end{abstract}

RESUMEN: Un estudio del estado actual de la regulación colombiana de las relaciones privadas internacionales revela importantes carencias en lo referente a todos los sectores que integran el Derecho internacional privado (DIPr). En este contexto, la Ley Modelo OHADAC de DIPr presentada el pasado mes de abril de 2014 representa una opción de máximo interés. Colombia necesita acometer con urgencia una revisión en profundidad de su DIPr, y a tal fin debería contar con esta Ley modelo, integrada por normas modernas y sencillas, adaptadas a las exigencias actuales y a los modelos generados por la globalización en general y los movimientos regionales de integración en particular.

PALABRAS CLAVE: Colombia - OHADAC - Derecho internacional privado - Codificación - Ley modelo de DIPr

ABSTRACT: A revision of the current state of the Colombian regulation of international private relations reveals significant gaps in all the Private International Law (PIL) sectors. In this context, the OHADAC Model Law on PIL, filed in April 2014, represents an instrument of maximum interest. Colombia is in urgent need of a thorough revision of its PIL rules, and, to accomplish this task, the law maker should count on this Model Law, constituted by modern and simple rules, which are adapted to the modern requirements and to the models generated by globalization in general and regional integration movements in particular.

KEYWORDS: Colombia - OHADAC - Private International law - Codification - Model Law on PIL

\section{Introducción}

El pasado mes de abril de 2014 se presentaba una Ley Modelo de DIPr para el ámbito de la OHADAC. Este texto propone normas de DIPr claras, sencillas y que proporcionan soluciones ajustadas a la realidad actual de las relaciones privadas internacionales, en lo referente a la totalidad de los sectores del DIPr; pero, además, constituye un magnífico modelo de sistema de DIPr.

Ciertamente, cabe emplear la Ley Modelo OHADAC de DIPr para adaptar los sectores de las normativas de DIPr de los países caribeños que precisen de puntuales renovaciones o mejoras. Pero el texto proporciona, esencialmente, la posibilidad de realizar una revisión profunda de la regulación estatal, que permita dotarse de un verdadero sistema de DIPr a los Estados que carecen de él. Y cabe avanzar que esta es la situación del DIPr en Colombia.

El presente trabajo analiza el DIPr de Colombia, a fin de determinar en qué medida este Estado caribeño precisa acometer una reforma de esta rama del ordenamiento. Al efecto, se estudiarán los distintos sectores que conforman el DIPr: competencia judicial internacional, Derecho aplicable, reconocimiento y ejecución de resoluciones judiciales y cooperación internacional entre autoridades, distinguiendo entre la regulación interna y los convenios internacionales en vigor en Colombia en cada uno de esos sectores (aptdo. II). A continuación se analizará el papel que desempeña la jurisprudencia en la materia (aptdo. III); y, finalmente, se propondrán las conclusiones que quepa derivar del estudio (aptdo. IV). 


\section{Carácter incompleto y disperso del actual Derecho internacional privado}

\section{Competencia judicial internacional}

A) Regulación estatal

El sector de la competencia judicial internacional acusa destacadamente la inadecuación de la normativa estatal a las situaciones privadas internacionales. De hecho, ni siquiera existen normas específicas sobre el particular: el Código General del Proceso (CGP), al margen de ciertas disposiciones sobre inmunidad de jurisdicción (art. 27), únicamente contiene normas de competencia territorial (principalmente, en la actualidad, el art. 28), que se aplicarían a la determinación de la competencia internacional, con resultados indeseables, en especial en lo que respecta a determinadas materias (como la contractual). La reciente reforma de este texto, a través de la Ley 1564 de 12 de julio de $2012^{1}$, no ha introducido mejora ninguna en lo relativo a este sector.

El DIPr colombiano de fuente estatal responde a un modelo monista: un juez colombiano resultará competente en situaciones litigiosas internacionales si las normas de competencia territorial le atribuyen competencia ${ }^{2}$. De esta forma, los órganos jurisdiccionales colombianos conocerán con base en el foro general del domicilio del demandado o el del domicilio de uno de los demandados, si concurre una pluralidad de demandados; o el de su residencia, si el demandado carece de domicilio en Colombia, e incluso, el del domicilio o la residencia del demandante, si el demandado carece también de residencia en el país (art. 28.1 CGP). Además, se acogen, entre otros, para materias familiares el foro del domicilio del demandante, si coincide con el domicilio conyugal común anterior (art. 28.2 CGP); para procesos de alimentos, filiación y responsabilidad parental, el del domicilio o la residencia habitual del menor (art. 28.3 CGP); para procesos originados en un negocio jurídico o que involucren títulos, el forum executionis (art. 28.3 CGP); para materia societaria (nulidad, disolución y liquidación de sociedades, y controversias entre socios), el foro del domicilio principal de la sociedad (art. 28.4 CGP) y, en lo referente a litigios relativos a la explotación de sucursales, el foro de la sucursal (art. 28.5 CGP); en materia extracontractual, el locus damni (art. 28.6 CGP); en procesos sobre derechos reales, el locus rei sitae (art. 28.7 CGP); en materia de quiebra, el del domicilio del deudor o, si hubiere tenido varios, el que corresponda al asiento principal de sus negocios (art. 28.8 CGP); y para procesos sucesorios, el último domicilio del causante o, si hubiere tenido varios, el que corresponda al asiento principal de sus negocios (art. 28.12 CGP).

Lo inconveniente de la extensión de estas normas al ámbito de la competencia judicial internacional se ha puesto de manifiesto, especialmente, en lo que respecta al ámbito contractual, dada la ineficacia que tendría, con arreglo a la normativa existente, todo acuerdo de elección de tribunal ${ }^{3}$. Antes de la reforma de julio de 2012, eran dos los elementos que permitían deducir tal ineficacia: por una parte, que las normas de competencia (territorial), atribuían competencia en materia contractual a los tribunales del lugar de ejecución del contrato y a los tribunales del domicilio del demandado, o, siendo éste persona jurídica, del lugar de la sucursal con la que se vincula el litigio; y, por otra parte, que el art. 13 CGP preveía la improrrogabilidad de la competencia territorial. Con la referida reforma, se ha derogado este precepto, pero sigue existiendo otra norma que imposibilita la sumisión expresa: el último

\footnotetext{
${ }^{1}$ Diario Oficial núm. 48.489 de 12 de julio de 2012. La anterior norma de competencia territorial se disponía en el art. 23. Esta Ley 1546 ha derogado también el art. 13 CPC, al que más adelante se hace mención.

${ }^{2}$ A lo que habría que añadir el requisito de que la controversia tenga un punto de contacto material con Colombia, según (aunque sin mayor explicación) A. Zuleta Londoño, "Las cláusulas de selección de foro y selección de ley en la contratación internacional: una visión desde el Derecho internacional privado colombiano", Revista de Derecho Privado (Universidad de los Andes) núm. 44, julio-diciembre de 2010, pp. 1-20, disponible en http://derechoprivado.uniandes.edu.co/.

${ }^{3}$ Vid. ibidem., nota 43, pp. 21 y ss. Aboga por la inaplicación de las normas territoriales a los supuestos internacionales N. Londoño Sepúlveda, en “El riesgo en la contratación internacional”, en http://www.decconsultores.com/index.php/articulos/185-competenciainternacional.
} 
inciso del art. 25.3 (ex 23.5) CGP, que declara que se tendrá por no escrita la estipulación del domicilio contractual a efectos judiciales.

Si el sistema autónomo carece de normas de competencia judicial internacional, no puede sorprender que tampoco existan normas sobre la aplicación de dichas normas. No se hallará, por tanto, una regulación de cuestiones tales como el control de la competencia internacional, la litispendencia y la conexidad internacional o la derogatio fori. En relación con ésta, y a tenor de la normativa antes citada, esto es, invocando el (actual 28.3 CGP y) antiguo art. 23.5 CGP (entre otros argumentos), el Tribunal Superior de Distrito Judicial de Bogotá ha negado de forma reiterada la eficacia de cláusulas de elección de foro a favor de tribunales extranjeros ${ }^{4}$.

\section{B) Convenios internacionales}

La normativa estatal podría verse desplazada por las disposiciones de instrumentos convencionales, tanto multilaterales como bilaterales, que mejorasen la situación. Sin embargo, los instrumentos internacionales vigentes en Colombia presentan un ámbito de aplicación interpartes que reduce significativamente esa posibilidad.

En efecto, sólo caso de que la cuestión litigiosa esté vinculada con al menos dos Estados contratantes $^{5}$, resultará de aplicación el correspondiente Tratado de Montevideo de 1889: el de Derecho civil internacional ${ }^{6}$ o el de Derecho comercial internacional ${ }^{7}$; sólo si se trata de una situación vinculada a Colombia y Ecuador, se aplicará el Tratado sobre Derecho internacional privado entre Colombia y Ecuador, hecho en Quito el 18 de junio de $1903^{8}$; y, en materia de alimentos, la competencia vendrá determinada por la Convención interamericana sobre obligaciones alimentarias de $1989^{9}$, únicamente cuando el acreedor de alimentos tenga su

\footnotetext{
${ }^{4}$ Vid. Auto de 27 de marzo de 2009, citado en A. Zuleta Londoño, loc. cit., nota 43, p. 24, en http://portal.uexternado.edu.co/pdf/Derecho/derecho_procesal/providenciaReferenciada/B24C4.pdf. Vid. también, del mismo órgano judicial, Auto de 30 de abril de 2002.

${ }^{5}$ Este el ámbito de aplicación espacial (inter-partes) es el que parece desprenderse, en defecto de disposición expresa al respecto, de la lectura de los asuntos publicados en Los Tratados de Montevideo de 1889 y su interpretación judicial, vol. I, parte $1^{\text {a }}$, Universidad Nacional de La Plata, Argentina, 1940.

${ }^{6}$ Tratado de Derecho Civil Internacional de Montevideo de 12 de febrero de 1889, al que se adhirió Colombia por Ley 40 de 1933 (la referencia de esta ley, y de todas las siguientes, se toma de J.L. Marín Fuentes, "Estado del Derecho Internacional Privado en Colombia y su enseñanza", disponible en http://asadip.files.wordpress.com/2009/11/ensenanza-del-derecho-internacional-privado-en-

colombia.pdf). Colombia no ha ratificado las reformas operadas sobre este Tratado por el posterior de Montevideo de 1940.

${ }^{7}$ Tratado de Derecho Comercial Internacional de Montevideo de 12 de febrero de 1889, adoptado por Ley 40 de 1933.

${ }^{8}$ Adoptado el 16 de junio de 1903, Registro Oficial, núm. 189, de 19 de julio de 1933. http://190.24.134.121/webcsj/Documentos/Civil/Exequ\%C3\%A1tur\%20V.\%20Final/Instrumentos\%20Int ernacionales/Tratado\%20sobre\%20Derecho\%20Internacional\%20privado\%20entre\%20las\%20Rep\%C3 \%BAblicas\%20de\%20Colombia\%20y\%20el\%20Ecuador.pdf.

${ }^{9}$ Convención interamericana sobre obligaciones alimentarias, hecha en Montevideo el 15 de julio de 1989 (CIDIP IV), aprobada por Ley 449, de 4 de agosto de 1998. Este texto fue firmado el 15 de julio de 1989; se realizó la correspondiente adhesión el 20 de mayo de 2010, y el depósito el 28 de julio de 2010, con una declaración relativa a los arts. 1 y 3 de la Convención (Declaración al ratificar la Convención): “ $a$. $L a$ República de Colombia, en relación con el Artículo 1 de la Convención declara que de conformidad con el artículo 344 de la Constitución Política, los derechos de los niños prevalecen sobre los derechos de los demás. b. La República de Colombia, teniendo en cuenta la declaración anterior, en relación con el Artículo 3 de la Convención, manifiesta que de conformidad con su ordenamiento jurídico y sujeto a las reglas previstas en él, además de los acreedores a que se refiere el párrafo 2 del artículo 1 de la citada Convención, ésta se aplicará a favor de: los descendientes; los ascendientes; los hijos adoptivos; los padres adoptantes; los hermanos; la persona que hizo una donación cuantiosa si no hubiere sido rescindida o revocado; o el compañero o compañera permanente que forman una unión marital de hecho”.
} 
domicilio o residencia habitual en un Estado parte y el deudor de alimentos tenga su domicilio o residencia habitual, bienes o ingresos en otro Estado parte (art. 1) ${ }^{10}$.

Por tanto, por más que estos instrumentos puedan establecer normas de competencia judicial internacional ${ }^{11}$, sin duda más adecuadas que las normas territoriales de la normativa estatal, no se aplican sino a un número muy limitado de situaciones. La mayor parte de las situaciones privadas internacionales se regirán, en lo que a la determinación de la competencia judicial internacional respecta, por las normas estatales antes descritas.

\section{Determinación de la ley aplicable}

A) Regulación estatal

Tampoco las normas sobre Derecho aplicable del sistema autónomo colombiano contienen respuestas adecuadas a las situaciones privadas internacionales. Las principales disposiciones de

${ }^{10} \mathrm{Vid}$. el estado de firmas y ratificaciones en http://www.oas.org/juridico/spanish/firmas/b-54.html.

${ }^{11}$ El Tratado de Derecho civil internacional de 1889, en concreto, en sus arts. 56-67. Estos prevén que, para acciones personales, sean competentes los tribunales del lugar a cuya ley está sujeto el acto jurídico o a los del domicilio del demandado (art, 56); para declaración de ausencia, el juez del último domicilio del presunto ausente (art. 57); para juicios sobre capacidad o incapacidad de las personas, el juez del domicilio (art. 58); para acciones sobre ejercicio de la patria potestad y tutela y curatela sobre la persona de los menores e incapaces, ante los tribunales del domicilio de los padres, tutores o curadores (art. 59); para acciones sobre propiedad, enajenación o actos que afecten a bienes de incapaces, los jueces del lugar donde estén situados (art. 60); para el juicio de rendición de cuentas, los tribunales del lugar en el que fue discernido el cargo de tutor o curador (art. 61); en materia de nulidad del matrimonio, divorcio o cualquier otra que afecte a las relaciones personales de los esposos, los jueces del domicilio conyugal (art. 62); para resolver las cuestiones que surjan entre los esposos sobre enajenación u otros actos que afecten los bienes matrimoniales, los jueces del lugar en que estén ubicados esos bienes (art. 63); para medidas urgentes en materias familiares, los jueces del lugar de residencia de las personas (art. 64); para los juicios relativos a la existencia y disolución de cualquier sociedad civil, los del lugar de su domicilio (art. 65); para los juicios sucesorios, los del lugar de situación de los bienes hereditarios (art. 66) y para las acciones reales y mixtas, los tribunales del lugar en el que se encuentre el bien (art. 67). Por su parte, el Tratado de Derecho Comercial Internacional también contiene foros de competencia en disposiciones como los arts. 6 y 7 (foro de la sucursal y foro del domicilio en materia societaria), el art. 10 (foro del domicilio de la sociedad aseguradora para litigios relativos a contratos de seguro que se dirijan contra dicha sociedad; o el de su sucursal, en su caso); o los arts. 13, 15 y 18.

El tratado bilateral, en materia de competencia dispone, en el art. XXIV, un forum executionis invocable frente a los domiciliados en el otro Estado contratante ("Los que tengan domicilio establecido en la República, sean nacionales o extranjeros, y estén presentes o ausentes, pueden ser demandados ante los Tribunales territoriales para el cumplimiento de contratos celebrados en el otro país"); en el art. $\mathrm{XXV}$, un forum presentiae invocable frente a extranjeros, por nacionales o domiciliados en el foro ("También pueden serlo los extranjeros que se hallan el país, aunque no sean domiciliados, si esos contratos se hubieren celebrados con los nacionales o con los otros extranjeros domiciliados en la República"); y en el art. XXVI, un forum executionis frente a extranjeros en materia contractual, un forum rei sitae para acciones sobre derechos reales situados en el territorio y una disposición cuyo alcance resulta difícil de determinar ("Los extranjeros, aunque se hallen ausentes, pueden ser demandados ante los Tribunales de la Nación: $1^{\circ}$. Para que cumplan las obligaciones contraídas o que deben ejecutarse en la República; $2^{\circ}$ Cuando se intente contra ellos una acción real concerniente a bienes que tengan en la República; y $3^{\circ}$. Si se hubiere estipulado que el Poder Judicial de la República decida las controversias relativas a obligaciones contraídas en el otro país").

Por lo que respecta a la Convención sobre alimentos, con arreglo al art. 8 son competentes, a elección del acreedor, tanto los tribunales del lugar de residencia del acreedor como los de la residencia habitual del deudor, o los del lugar donde éste tenga bienes, ingresos o beneficios económicos, además de los tribunales a los que se sometan las partes. Por su parte, el art. 9 atribuye competencia a los tribunales antes indicados para acciones de incremento de los alimentos, y a los que hubieren conocido de la fijación de los alimentos, para su cese o reducción. 
este sector se encuentran en el Código civil de 1873 (en adelante Cc) ${ }^{12}$, concretamente en los arts. 18 a $21^{13}$. El art. 18 Cc, que reproduce el posterior art. 59 de la Ley 149 de 1888, dispone el principio de territorialidad absoluta de la ley colombiana, afirmando que "la ley es obligatoria tanto a los nacionales como a los extranjeros residentes en Colombia". Esto comporta que, en principio, sea la ley de Colombia la que aplique cualquier autoridad de este Estado a todo tipo de relación privada internacional. La aplicación de la ley extranjera no resulta, por consiguiente, posible ${ }^{14}$, más allá de lo que puedan establecer tratados o convenios que desplacen la normativa interna.

A continuación, los arts. 19, 20 y 21 Cc declaran la extraterritorialidad de la ley colombiana en algunas situaciones que se corresponden con cuestiones incluidas, respectivamente en el "estatuto personal"15, el "estatuto real"16 y el "estatuto formal"17.

Otras normas del propio Código civil contienen una regulación sustantiva de aspectos particulares de relaciones jurídicas, instituciones o negocios, tales como el matrimonio (art. 127), el divorcio (arts. 163 y 164), el régimen económico matrimonial (art. 180), la sucesión testada e intestada (arts. 570, 1012, 1053, 1054, 1068, 1012, 1084, 1085, 1086), y la hipoteca (art. 2436).

El Código de Comercio (en lo sucesivo Ccm) también contiene disposiciones de carácter material que regulan instituciones, relaciones o negocios jurídicos con elemento extranjero, tales como el art. $80 \mathrm{Ccm}$ (prueba de la costumbre extranjera) o el art. $874 \mathrm{Ccm}$ (pago en moneda extranjera). No obstante, desde la óptica del DIPr interesan en especial el art. $869 \mathrm{CCm}$, que regula la ley aplicable a los contratos internacionales con carácter general, siguiendo idéntica

\footnotetext{
${ }^{12}$ Código que deriva directamente del Código chileno de Andrés Bello de 1855. En consecuencia, tal y como ocurre con éste, encuentra sus fuentes fundamentales en el Derecho romano, el Derecho español y el Code Napoleon. Vid. J.C. Fernández Rozas, "El Código de Napoleón y su influencia en América Latina: reflexiones a propósito del Segundo Centenario”, El Derecho internacional en tiempos de globalización: libro homenaje a Carlos Febres Pobeda, Universidad de los Andes, Publicaciones del Vicerrectorado Académico, Mérida (Venezuela), 2005, pp. 151-190, esp. pp. 177-178. Vid. también C. Hertel, “Sistemas y familias jurídicos del mundo”, Notarius International, 1-2, 2009, pp. 185-200, esp. p. 191 (disponible en http://www.notariusinternational.uinl.org/DataBase/2009/Notarius_2009_01_02_hertel_es.pdf).

${ }^{13} \mathrm{Si}$ se compara estos artículos (reproducidos más adelante, en las notas 15 y 16) con los arts. 14-18 Cc chileno, se comprobará la práctica identidad existente entre ambos, también en lo que respecta a las normas de DIPr.

${ }^{14}$ Cf. J.J. Caicedo Castilla, Derecho internacional privado, 6aed., Bogotá, Themis, 1967, p. 244.

${ }^{15}$ En concreto, el art. 19 Cc prevé que "los colombianos residentes o domiciliados en país extranjero permanecerán sujetos a las disposiciones de este código y demás leyes nacionales que reglan los derechos y obligaciones civiles:

1. En lo relativo al estado de las personas para efectuar ciertos actos que hayan de tener efecto en alguno de los territorios administrados por el gobierno general, o en asuntos de la competencia de la Unión.

2. En las obligaciones y derechos que nacen de las relaciones de familia, pero sólo respecto de sus cónyuges y parientes en los casos indicados".

${ }^{16} \mathrm{El}$ art. 20 Cc establece que "Los bienes situados en los territorios y aquellos que se encuentran en los Estados, en cuya propiedad tenga interés o derecho la Nación, están sujetos a las disposiciones de este código, aún cuando sus dueños sea extranjeros y residan fuera de Colombia. Esta disposición se entenderá sin perjuicio de las estipulaciones contenidas en los contratos celebrados válidamente en país extraño. Pero los efectos de dichos contratos, para cumplirse en algún territorio, o en los casos que afecten a los derechos e intereses de la Nación, se arreglan a este código y demás leyes civiles de la Unión”.

${ }^{17}$ Art. 21 Cc: "La forma de los instrumentos públicos se determina por la ley del país en que hayan sido otorgados. Su autenticidad se probará según las reglas establecidas en el código judicial de la unión. La forma se refiere a las solemnidades externas, a la autenticidad, al hecho de haber sido realmente otorgados y autorizados por las personas y de la manera que en tales instrumentos se exprese”.
} 
técnica legislativa unilateralista que las previsiones del Cc antes citadas ${ }^{18}$; y el art. 1328 CCm, que regula el contrato de agencia. De estas disposiciones también deriva que, en principio, la ley aplicable al contrato (al menos a las cuestiones de fondo) ${ }^{19}$ será siempre la colombiana si el contrato debe ejecutarse en Colombia ${ }^{20}$; por ende, si se trata de un contrato de compraventa internacional de mercaderías, será la Convención de Viena de 1980 sobre compraventa internacional de mercaderías ${ }^{21}$ la que se aplique ${ }^{22}$.

De esta forma, en lo que respecta a la regulación conflictual, el Derecho colombiano, como se ha avanzado, es claramente deficitario, con carácter general. Pero hay un ámbito en el que su insuficiencia se hace especialmente manifiesta, y es el contractual, toda vez que aún resulta discutido e incierto si, fuera del arbitraje $e^{23}$, cabe o no la posibilidad de escoger una ley extranjera como reguladora del contrato $^{24}$. La incógnita no parece despejada, aunque la jurisprudencia nacional habría asumido en los últimos años una posición favorable a la validez de pacto de ley extranjera, e incluso habría afirmado la autonomía de la voluntad también en lo que respecta a la sujeción de un contrato a los Principios Unidroit ${ }^{25}$.

Finalmente, interesa advertir que el sistema autónomo colombiano carece de normas de aplicación de las normas de conflicto, lo que en cierto modo no extraña, teniendo en cuenta que el punto de partida es de rechazo a la aplicación de leyes extranjeras. No se hallará, pues, ninguna previsión específica en la normativa estatal sobre calificación, reenvío, remisión a Estado plurilegislativo, fraude de ley, prueba del Derecho extranjero u orden público (internacional).

\section{B) Convenios internacionales}

En el sector de la ley aplicable, son varios los convenios o tratados que pueden desplazar las soluciones estatales.

\footnotetext{
${ }^{18}$ Confirmando el referido principio de territorialidad de la ley colombiana, establece el art. $869 \mathrm{Ccm}$ : "Ejecución en el país de contratos celebrados en el exterior. La ejecución de los contratos celebrados en el exterior que deban cumplirse en el país, se regirá por la ley colombiana".

${ }^{19} \mathrm{La}$ forma del contrato se regiría por la ley extranjera del lugar de su celebración, si tal fuese el caso.

${ }^{20}$ Lo que no indica ninguno de estos preceptos es qué ocurre si el contrato se ejecuta parcialmente en el extranjero. Al respecto, vid. J. Oviedo Albán en "La ley aplicable a los contratos internacionales", Revista Colombiana de Derecho Internacional, núm. 21, 2012, pp. 117-157, esp. p. 132.

${ }^{21}$ Convención de las Naciones Unidas sobre los contratos de compraventa internacional de mercaderías, hecha en Viena el 11 de abril de 1980, aprobada por Ley 518 de 4 de agosto de 1999. La fecha de adhesión es de 10 de julio de 2001, y entró en vigor el 1 de agosto de 2002. No hay reservas ni declaraciones por parte de Colombia.

${ }^{22}$ Pues, salvo que se excluya expresamente por los contratantes (ex art. 6 CV 1980), la CV 1980 se aplicará cuando las partes están establecidas en Estados contratantes diferentes, con arreglo al art. 1.a), pero también cuando la ley aplicable según la norma de conflicto del foro sea la de un Estado contratante, según el art. 1.b) (cuya aplicación Colombia no ha reservado). Así, la CV 1980 se aplicará siempre que deben aplicarse las normas de conflicto estatales, ya que éstas declaran aplicable la lex fori (ley de un Estado contratante)

${ }^{23}$ Los árbitros deben aplicar al fondo del asunto la ley elegida por las partes, según lo dispuesto en el art. 101 de la Ley 1563, Por medio de la cual se expide el Estatuto de Arbitraje Nacional e Internacional y se dictan otras disposiciones. Este texto se encuentra disponible en la web: http://www.camaraarmenia.org.co/files/LEY1563DE2012ARBITRAJE(1).pdf.

${ }^{24}$ Realiza una lectura favorable a esta posibilidad (“implícita” en la norma), en lo que a todos los contratos, salvo el de agencia, respecta, J. Oviedo Albán en "La ley aplicable a los contratos internacionales", loc. cit., pp. 124-126. El autor, no obstante, es crítico con la regulación colombiana: "las normas de conflicto contenidas en los Códigos Civil y de Comercio son poco claras y por su rigidez no resultan adecuadas para satisfacer los intereses de las partes en negocios internacionales (p. 118). De otra opinión (negativa a dicha posibilidad), A. Zuleta Londoño, "Las cláusulas de selección de foro...", loc. cit., pp. 18-20.

${ }^{25}$ Vid. infra, aptdo. IV, en el que se exponen sintéticamente las líneas jurisprudenciales.
} 
Los Convenios de Montevideo de 1889 (de Derecho Civil Internacional y de Derecho Comercial Internacional), y el Tratado sobre Derecho Internacional privado entre Colombia y Ecuador contienen normas de conflicto de carácter bilateral en diversas materias. Estos instrumentos, según se indicó antes, carecen de disposiciones claras sobre su aplicabilidad espacial, pero todo indica que se aplicarían inter-partes, por lo que, aunque puedan contener soluciones más adaptadas, constituyen sólo una mejora parcial.

Así, por ejemplo, en materia contractual, el Tratado de Montevideo de Derecho Civil Internacional de 1889 y el Tratado de DIPr entre Colombia y Ecuador ${ }^{26}$ declaran aplicable al contrato la lex loci executionis ${ }^{27}$. Ello comportará que, si se trata de una compraventa cubierta por la Convención de Viena de 1980 (CV 1980) tanto en lo referente a la materia (art. 2) como al tiempo (art. 100), será ésta la que la aplicable en la práctica totalidad de los supuestos. En efecto, sólo resultará posible aplicar una ley extranjera si resulta de aplicación alguno de los tratados anteriormente citados (el de Montevideo o el bilateral), y éste no remite a la ley de un Estado parte del CV 1980. Y, como a excepción de Bolivia, todos los Estados parte del Tratado de Montevideo son también parte de la CV $1980^{28}$, si el Tratado resulta de aplicación, la propia CV 1980 se aplicará: o por la vía del art. 1.1.a) CV 1980, o porque la ley aplicable según el DIPr (el Tratado) será la de un Estado contratante ${ }^{29}$. Sólo hay una posibilidad de que la CV 1980 no se aplique, y es que el contrato, celebrado entre una parte colombiana y otra establecida en Bolivia (o en algún otro Estado no parte de la CV 1980) se ejecute en Bolivia.

Otras materias reguladas por instrumentos específicos en las que existen normas sobre la ley aplicable son la adopción (Convención interamericana sobre adopción de La Paz de 1984) ${ }^{30}$ y las obligaciones de alimentos (Convención interamericana sobre obligaciones alimentarias) ${ }^{31}$.

La inexistencia de soluciones estatales a los problemas de aplicación de las normas de conflicto también puede verse en parte remediada por las disposiciones de la Convención interamericana sobre normas generales de Derecho internacional privado, de Montevideo de $1979^{32}$. En efecto, este es el único instrumento que, con carácter general, proporciona normas sobre aplicación de la ley extranjera: orden público, fraude de ley, aplicación de la ley extranjera, fraude de ley... Pero, aunque esta Convención no indica expresamente a qué relaciones, situaciones o negocios jurídicos resulta de aplicación, todo indica que también se trata de un instrumento inter-partes, aplicable sólo en la medida en que la ley aplicable sea la de

\footnotetext{
${ }^{26}$ Estos Convenios, como ya se ha puesto de manifiesto, se aplicarían únicamente en la medida en que la ley aplicable sea la de un Estado contratante.

${ }^{27}$ Vid. arts. 32-39.

${ }^{28}$ Vid. http://www.uncitral.org/uncitral/es/uncitral_texts/sale_goods/1980CISG_status.html.

${ }^{29}$ Pues cabe recordar que, si resultan de aplicación el Tratado de Montevideo de Derecho Comercial Internacional de 1889 o el Tratado de DIPr entre Colombia y Ecuador, la ley rectora del contrato sería la lex loci executionis.

${ }^{30}$ Convención interamericana sobre conflicto de leyes en materia de adopción de menores, adoptada en La Paz el 24 de mayo de 1984 (CIDIP III), aprobada por Colombia por Ley 47, de 3 de diciembre de 1987. Esta Convención fue firmada el 24 de mayo de 1984, se realizó la adhesión el 15 de marzo de 1988, y el depósito el 26 de abril de 1988, sin reservas ni declaraciones. Su art. 1 exige, a efectos de aplicación, que el adoptante (o adoptantes) tenga(n) su domicilio en un Estado Parte y el adoptado su residencia habitual en otro Estado Parte. Las principales disposiciones sobre ley aplicable se encuentran en los arts. $3,4, \mathrm{y} 6$.

31 Sobre la aplicación espacial de esta Convención, vid. supra, nota xx. Las normas de conflicto se recogen en los arts. 6 y 7. Conforme al art. 6, la autoridad competente ha de aplicar la ley que resulte más favorable al interés del acreedor, de entre la ley del domicilio o la residencia habitual del acreedor, o la ley del domicilio o de la residencia habitual del deudor. El art. 7 delimita el ámbito de la ley aplicable.

${ }^{32}$ Aprobada por Ley 21, de 22 de enero de 1981, fue firmada el 5 de agosto de 1979, se realizó la adhesión el 9 de junio de 1981, y el depósito de ratificación el 10 de septiembre de 1981, sin reservas ni declaraciones.
} 
un Estado contratante del Convenio ${ }^{33}$. De nuevo, la existencia de este Convenio no constituye un remedio total para las importantes deficiencias del sistema autónomo.

\section{Reconocimiento y ejecución de decisiones extranjeras}

A) Regulación estatal

La regulación del reconocimiento y ejecución de decisiones extranjeras se encuentra contenida en los arts. 30 y 605 y ss. CGP (antiguos arts. 25 y 693 y ss. CGP). Se trata de un régimen de reconocimiento caduco, al menos en lo que respecta a la exigencia de reciprocidad del país de origen. Sorprende, pues, que el legislador haya acometido recientemente una reforma de estas disposiciones, sin que el régimen se haya visto mejorado en este extremo.

En efecto, a tenor de lo previsto en los arts. 605 y ss. CGP, la parte que solicita el reconocimiento de la decisión extranjera debe probar reciprocidad, además de una serie de condiciones (previstas en el art. 606 CGP).

La prueba de la reciprocidad (exigida por el actual art. 605 CGP, antiguo art. 693 CGP) viene refiriéndose a la existencia de convenio de reconocimiento con el país de origen (reciprocidad "diplomática”), pero también a la posibilidad de reconocimiento de sentencias colombianas en dicho país ${ }^{34}$. De esta forma, si no existe "reciprocidad diplomática", deben probarse la "reciprocidad legislativa" y el cumplimiento de las condiciones dispuestas en el art. 606 CGP (ex art. 694 CGP) ${ }^{35}$. Sintéticamente, este precepto dispone un control de competencia, conforme al cual no cabe reconocer ni sentencias que versen sobre bienes situados en territorio colombiano (aptdo. 1) ni en materias para las que los tribunales colombianos tengan atribuida competencia exclusiva (aptdo. 4); control de orden público (aptdo. 2); control de regularidad formal (aptdo. 3); inexistencia de procedimiento abierto en Colombia, o sentencia dictada por jueces colombianos sobre el mismo asunto (aptdo. 5); control de la regularidad de la notificación, de conformidad con la ley del país de origen (aptdo. 6); y que se tramite el procedimiento dispuesto en el siguiente artículo (aptdo. 7).

\footnotetext{
${ }^{33}$ En la actualidad, junto con Colombia, Argentina, Brasil, Ecuador, Guatemala, México, Paraguay, Perú, Uruguay y Venezuela (vid. http://www.oas.org/juridico/spanish/firmas/b-45.html).

${ }^{34}$ Es doctrina consolidada de la Corte Suprema de Justicia entender que "por regla general, las decisiones judiciales extranjeras no se pueden hacer valer en Colombia y en que, por excepción, cobran vigor siempre y cuando exista con el país extraño un tratado que así lo consagre -reciprocidad diplomática- o falta de convenio internacional, exista ley, allá mismo, que le otorgue valor a las sentencias proferidas oír los jueces colombianos -reciprocidad legislativa-. Por virtud del principio de la carga probatoria que impone el artículo 177 del CPC, en cualquiera de las hipótesis de excepción mencionadas, le corresponde al solicitante del exequátur demostrar, previas las formalidades legales pertinentes, la existencia del respectivo tratado o de la ley extranjera, presupuesto indispensable para que pueda la Corte examinar otras condiciones e incidencias propias de la solicitud de la que se trata": vid. Sentencia T-716/96 de la Corte Constitucional colombiana, disponible en http://www.corteconstitucional.gov.co/relatoria/1996/t-716-96.htm.

${ }^{35}$ Como deriva de la Sentencia T-716/96, antes citada, "la actividad del actor del exequátur debe estar orientada a demostrar la existencia de la reciprocidad diplomática o, en su defecto, de la legislativa, de conformidad con lo establecido por el art. 177 del C. de P.C., que impone a las partes "probar el supuesto de hecho de las normas que consagran el efecto jurídico que ellos persiguen". Si se cumplen esas exigencias el exequátur deberá otorgarse siempre que se den además los restantes requisitos previstos en el art. 694 de la misma obra, requisitos cuyo sentido general no es otro que el de establecer la regularidad internacional de la sentencia, sin entrar a calificar la justicia intrínseca de primera decisión jurisdiccional mediante dicha providencia adoptada". Vid. también las decisiones de la Sala de Casación Civil de la Corte Suprema de Justicia de 13 de agosto de 2002 y de 13 de febrero de 2004, ambas disponibles en https://sites.google.com/site/misclasesenderecho/reconocimiento-de-sentenciasextranjeras-exequatur.
} 
Para conocer de solicitudes de exequátur se otorga competencia a un único tribunal: la Sala de Casación Civil de la Corte Suprema de Justicia (art. 30.4 CGP, ex art. 25.4 CGP) ${ }^{36}$. El art. 607 CGP regula el procedimiento, cuyas características principales son que se trata de un procedimiento contradictorio y documental.

\section{B) Convenios internacionales}

En materia de reconocimiento y ejecución de resoluciones extranjeras, no son muy numerosos los instrumentos adoptados por Colombia.

Son dos los tratados bilaterales generales: el vigente entre Colombia y España, sobre reconocimiento de sentencias ${ }^{37}$, y el ya mencionado, de Derecho internacional privado, entre Colombia y Ecuador ${ }^{38}$.

A los bilaterales se suman otros convenios, también generales, pero de carácter multilateral, como el Tratado de Derecho Procesal Internacional de Montevideo de $1889^{39}$ y la Convención interamericana sobre eficacia extraterritorial de las sentencias y los laudos arbitrales extranjeros $^{40}$.

Y a los anteriores se añaden convenios multilaterales en materias específicas, tales como la adopción internacional (Convenio de 29 de mayo de 1993 relativo a la protección del niño y a la cooperación en materia de adopción internacional ${ }^{41}$ ), las obligaciones de alimentos (Convención interamericana sobre obligaciones alimentarias) y el reconocimiento de laudos extranjeros (Convención de Nueva York de 1958 para el reconocimiento laudos arbitrales extranjeros ${ }^{42}$ ).

\section{Cooperación internacional entre autoridades}

El sistema autónomo colombiano carece de toda disposición que regule específicamente la cooperación de las autoridades colombianas con autoridades extranjeras (solicitudes de aquéllas a éstas, y viceversa) en actos dirigidos a facilitar el desarrollo de procedimientos con elementos extranjeros, tales como práctica de pruebas, traslado y la notificación de documentos, o prueba del contenido, la vigencia y la interpretación del Derecho extranjero.

\footnotetext{
${ }^{36} \mathrm{Si}$ bien sus decisiones serían revisadas en una segunda instancia por el Consejo Superior de la Judicatura, Sala Jurisdiccional Disciplinaria, según se deduce de lo expuesto en la Sentencia T-716/96 de la Corte Constitucional colombiana, cit.

${ }^{37}$ Convenio para el cumplimiento de las sentencias civiles dictadas por los tribunales de ambos países, celebrado entre el Reino de España y la República de Colombia el 30 de mayo de 1908, BOE núm. 108/1909, de 18 de abril de 1909. Este Convenio es aplicado frecuentemente en la práctica, especialmente en lo que respecta al reconocimiento de decisiones españolas en materia de adopción (no reguladas por el CH de 1993 cuando el o la menor no van a trasladarse a Colombia). Vid., v.gr., entre otras, las Sentencias de la Sala de Casación Civil de la Corte Suprema de Justicia de 5 de noviembre de 2013, de 16 de octubre de 2013, de 25 de julio de 2013, de 16 de mayo de 2013, todas ellas publicadas y disponibles en la web del órgano jurisdiccional: http://190.24.134.92:8085/Relatoria/csj/index.html

${ }^{38}$ Las normas de reconocimiento de sentencias se encuentran en los arts. XXXIX-XLIX.

${ }^{39}$ Aprobado por Ley 68 de 1920. Vid. arts. 5- 8.

${ }^{40}$ Convención interamericana sobre eficacia extraterritorial de las sentencias y los laudos arbitrales extranjeros, hecha en Montevideo el 5 de agosto de 1979 (CIDIP II) aprobada por Ley 16, de 22 de enero de 1981 y firmada el 5 de agosto de 1979. La adhesión se realizó el 24 de junio de 1981, y el depósito, el 10 de septiembre de 1981, sin reservas ni declaraciones

${ }^{41}$ Se aprueba por Ley 265 de 25 de enero de 1996. Firma: 1 de agosto de 1993. Fecha de adhesión: 13 de julio de 1998. Entrada en vigor: 1 de noviembre de 1998. Colombia formula una declaración referente a los artículos 17, 21, 22 y 28 del Convenio. Este Convenio, como es sabido, regula principalmente la cooperación internacional entre autoridades, pero contiene también normas de reconocimiento de las adopciones constituidas ante autoridades de Estados contratantes.

${ }^{42}$ Convención sobre el reconocimiento y la ejecución de sentencias arbitrales extranjeras, hecha en Nueva York el 10 de junio de 1958. Se aprueba por Ley 39 de 20 de noviembre de 1990. Fecha de adhesión: 25 de septiembre de 1979. Fecha de entrada en vigor: 24 de diciembre de 1979. No hay reservas ni declaraciones por parte de Colombia.
} 
De ahí que resulte particularmente relevante la participación de Colombia en los resultados de las diversas sedes codificadoras en el sector de la competencia internacional entre autoridades. Y es este el sector en el que más convenios ha adoptado este país.

El primero de los textos adoptados fue el ya citado Tratado de Derecho Procesal Internacional de Montevideo de $1889^{43}$. Posteriormente, y a pesar de no ser Estado miembro de la Conferencia de La Haya, de esta sede, Colombia ha ratificado el Convenio de 5 de octubre de 1961, suprimiendo la exigencia de legalización de los documentos públicos extranjeros ${ }^{44}$; el Convenio de 15 de noviembre de 1965 sobre la notificación o traslado en el extranjero de documentos judiciales y extrajudiciales en materia civil o comercial $^{45}$; el Convenio de 18 de marzo de 1970 sobre la obtención de pruebas en el extranjero en materia civil o comercial $^{46}$; el Convenio de 25 de octubre de 1980 sobre los aspectos civiles de la sustracción internacional de menores ${ }^{47}$; y el (ya citado) Convenio de 29 de mayo de 1993 relativo a la protección del niño y a la cooperación en materia de adopción internacional ${ }^{48}$.

Finalmente, entre los instrumentos ratificados por Colombia en materia de cooperación internacional, también ocupan un puesto destacable los elaborados en la CIDIP. Son, en concreto, la Convención interamericana sobre exhortos o cartas rogatorias, adoptada en Panamá el 30 de enero de 1975 (CIDIP I) ${ }^{49}$ y el Protocolo adicional a la Convención interamericana sobre exhortos o cartas rogatorias, hecho en Montevideo el 5 de agosto de 1979 (CIDIP II) ${ }^{50}$, la Convención interamericana sobre recepción de pruebas en el extranjero, adoptada en Panamá el 30 de enero de 1975 (CIDIP I) ${ }^{51}$, la Convención interamericana sobre cumplimiento de medidas cautelares, hecha en Montevideo el 5 de agosto de 1979 (CIDIP II) ${ }^{52}$, la Convención interamericana sobre prueba e información acerca del Derecho extranjero, hecha en Montevideo el 5 de agosto de 1979 (CIDIP II) ${ }^{53}$, la Convención interamericana sobre restitución internacional de menores, hecha en Montevideo el 15 de julio de 1989 (CIDIP IV) ${ }^{54}$ y la Convención interamericana sobre tráfico internacional de menores, hecha en México el 18 de marzo de 1994 (CIDIP V) ${ }^{55}$.

43 Que, además de disposiciones sobre reconocimiento y ejecución, contiene normas sobre legalizaciones (arts. 3 y 4), y exhortos y obtención de pruebas (arts. 9-12).

${ }^{44}$ Aprobado por Ley 455 de 4 de agosto de 1998. Fecha de adhesión: 27 de abril de 2000. Entrada en vigor: 30 de enero de 2001. Hasta el momento, Colombia ha realizado tres declaraciones, relativas a la forma en que se expide la apostilla en este Estado (incluida apostilla electrónica o e-Apostilla).

${ }^{45}$ Que se aprueba por Ley 1073 de 31 de julio de 2006. Fecha de adhesión: 10 de abril de 2012. Entrada en vigor: 1 de noviembre de 2013. No hay reservas ni declaraciones por parte de Colombia.

${ }^{46}$ Aprobado por Ley 1282 de 5 de enero de 2009. Fecha de adhesión: 13 de enero de 2012. Entrada en vigor: 13 de marzo de 2012. No hay reservas ni declaraciones por parte de Colombia.

${ }^{47}$ Se aprueba por Ley 173 de 22 de diciembre de 1994. Fecha de adhesión: 13 de diciembre de 1995. Entrada en vigor: 1 de marzo de 1996. No hay reservas ni declaraciones.

${ }^{48}$ Se aprueba por Ley 265 de 25 de enero de 1996. Firma: 1 de agosto de 1993. Fecha de adhesión: 13 de julio de 1998. Entrada en vigor: 1 de noviembre de 1998. Colombia formula una declaración referente a los artículos 17, 21, 22 y 28 del Convenio.

${ }^{49}$ Aprobada por Ley 27, de 22 de febrero de 1988. Firmada por Colombia el 30 de enero de 1975, la adhesión tuvo lugar el 17 de febrero de 1995 y el depósito el 28 de abril de 1995.

${ }^{50}$ Aprobado por Ley 27, de 22 de febrero de 1988. Fue firmado el 5 de agosto de 1979, se realizó la adhesión el 17 de febrero de 1995, y el depósito el 28 de abril de 1995, sin reservas ni declaraciones.

${ }^{51}$ Aprobada por Ley 31, de 9 de octubre de 1987. Firmada por Colombia el 30 de enero de 1975, la adhesión tuvo lugar el 27 de septiembre de 1991 y el depósito el 1 de noviembre de 1991.

${ }^{52}$ Aprobada por Ley 42 de 17 de septiembre de 1986, fue firmada el 5 de agosto de 1979, se realizó la adhesión el 19 de noviembre de 1986, y el depósito el 29 de diciembre de 1986, sin reservas ni declaraciones.

${ }^{53}$ Aprobada por Ley 49, de 16 de diciembre de 1982, fue firmada el 5 de agosto de 1979, se realizó la adhesión el 7 de febrero de 1983, y el depósito el 28 de abril de 1983, sin reservas ni declaraciones.

${ }^{54}$ Aprobada por Ley 880, de 19 de enero de 2004, fue firmada el 15 de julio de 1989, se realizó la adhesión el 12 de agosto de 1998, y el depósito el 28 de octubre de 1998, sin reservas ni declaraciones.

${ }^{55}$ Aprobada por Ley 470, de 5 de agosto de 1998, se realizó la adhesión el 12 de junio de 2000, y el depósito el 23 de agosto de 2000, sin declaraciones ni reservas. 


\section{El limitado papel de la jurisprudencia}

La jurisprudencia colombiana no resulta especialmente abundante en lo que respecta a las materias propias del $\operatorname{DIPr}^{56}$, probablemente porque el número de situaciones privadas internacionales de las que deben conocer las autoridades de Colombia sólo empieza a ser significativo en la actualidad ${ }^{57}$.

Cualitativamente, se trata de una jurisprudencia algo dispar: mientras que en algunas materias quizás se muestra en exceso pegada a la letra de unas normas que ni siquiera se dirigen a regular la cuestión a la que se aplican, en otras, sin embargo, parece proclive a efectuar una lectura de las normas de DIPr más conforme con las necesidades actuales. Ejemplo de lo primero es la negativa a reconocer eficacia a las cláusulas de elección de tribunal extranjero, con base en la improrrogabilidad de la competencia territorial. Y esta negativa es recogida en decisiones, como las de la Sala Civil del Tribunal Superior de Bogotá, que, sin embargo, admiten la eficacia de las cláusulas de elección de una ley extranjera en contratos internacionales ${ }^{58}$. En relación con el reconocimiento de la autonomía de la voluntad en materia contractual resulta también relevante la jurisprudencia de la Corte Suprema de Justicia colombiana $^{59}$, que se ha pronunciado favorable a la posibilidad de las partes de pactar como ley del contrato a los Principios Unidroit, además de la posibilidad de acudir a ellos para interpretar la ley nacional.

Finalmente, en el marco de la aplicación de las normas de reconocimiento y ejecución de resoluciones extranjeras, la doctrina de la Corte Suprema de Justicia resulta de especial interés en lo que respecta a la determinación del alcance de la reciprocidad y a la interpretación de conceptos jurídicos indeterminados, como el orden público. En relación con la reciprocidad, existe una línea jurisprudencial constante, que, como antes se indicó, diferencia entre reciprocidad "diplomática", consistente en la existencia y aplicabilidad de convenios internacionales ${ }^{60}$, y reciprocidad legislativa, que obliga a probar al solicitante del exequátur tanto la posibilidad de reconocimiento de las sentencias procedentes de Colombia en el Estado de origen, como el cumplimiento de los requisitos que en tal Estado de origen se exigen a las sentencias colombianas; requisitos que se suman a los previstos en la normativa colombiana ${ }^{61}$. En lo referido al orden público internacional, la Corte Suprema de Justicia ha declarado que se trata de una excepción oponible cuando se da “...una incompatibilidad grave entre el

${ }^{56}$ El trabajo de J.L. Marín Fuentes, "Estado del Derecho Internacional Privado en Colombia y su enseñanza”, loc. cit., hace referencia a un total de (tan solo) 50 decisiones de la Corte Suprema de Justicia en un periodo de 13 años (de 1995 a 2008), la mayor parte de las cuales versan sobre reconocimiento de decisiones extranjeras.

${ }^{57}$ Así lo afirma ibídem.

${ }^{58}$ Autos de la de 30 de abril del 2002 y 19 de diciembre del mismo año.

${ }^{59}$ Sentencia de la Sala de Casación Civil, de 21 de febrero de 2012, disponible en la web del órgano jurisdiccional: http://190.24.134.92:8085/Relatoria/csj/index.html

60 Por Sentencia de 3 de septiembre de 2013 (Magistrado Ponente Ariel Salazar Ramírez), la Sala de Casación de la Corte Suprema de Justicia considera que no hay reciprocidad diplomática porque, aunque el objeto del procedimiento es el reconocimiento de una adopción constituida en Connecticut, EEUU, que es parte, como Colombia, del Convenio de La Haya de 1993, éste no resulta aplicable, ya que ni la menor es trasladada de un Estado contratante a otro (permanece en EEUU), ni se han seguido los trámites dispuestos en el instrumento para constituir la adopción. La decisión puede consultarse en la web de la Corte: http://190.24.134.92:8085/Relatoria/csj/index.html

${ }^{61}$ Vid., además de las resoluciones citadas supra, entre otras, la Sent. de 3 de septiembre de 2013, en la que se afirma que "en primer lugar se atiende a las estipulaciones de los tratados que tenga celebrados Colombia con el Estado de cuyos tribunales emane la sentencia que se pretende ejecutar en el país. Y en segundo lugar, a falta de derecho convencional, se acogen las normas de la respectiva ley extranjera para darle a la sentencia la misma fuerza concedida por esa ley a las proferidas en Colombia.... Además del anterior requisito, para que un fallo extranjero surta efectos vinculantes en nuestro país se requiere que se cumplan los presupuestos que reclama el ordenamiento legal interno, específicamente los contenidos en el Capítulo I del Libro V del Título XXXVI del Código de Procedimiento Civil”. 
pronunciamiento jurisdiccional para el cual se pide el exequátur y los principios fundamentales en que se inspira la normatividad nacional...”, en cuyo caso "podría dar lugar a que aquélla no fuera objeto de homologación". Lo cual, significa que al albur de la excepción se deniega el reconocimiento de resoluciones extranjeras cuando el tribunal de origen ha aplicado leyes extranjeras que "se basan en principios no solo diferentes, sino contrarios a las instituciones fundamentales del país en que aquellas pretenden aplicarse (Colombia)"62. Para concluir, interesa advertir que son sorprendentemente numerosas las denegaciones de reconocimiento de resoluciones extranjeras por incumplimiento del requisito de la autenticidad, al menos en los últimos años ${ }^{63}$.

\section{Conclusiones}

Del análisis de las normas estatales de DIPr de Colombia se deduce que este Estado carece de un sistema completo y coherente de DIPr. Como se pone de relieve en este estudio, la regulación de los distintos sectores (competencia judicial internacional, Derecho aplicable, reconocimiento y ejecución de decisiones extranjeras, cooperación internacional entre autoridades), cuando existe, se encuentra en normas dispersas y poco (o nada) adecuadas a la resolución los diversos problemas del tráfico jurídico externo. Así, Colombia carece de normas estatales de competencia judicial elaboradas específicamente para las situaciones privadas internacionales, por lo que no extraña que tampoco cuente con normas de aplicación de estas normas, que resuelvan cuestiones tales como el control de la competencia, la litispendencia y la conexidad internacional y la derogatio fori. Las normas de conflicto, por su parte, resultan también manifiestamente inadecuadas, por cuanto impiden como línea de principio dar aplicación a leyes extranjeras. Tampoco hay, en consecuencia, normas de aplicación de las normas de conflicto. Para hallar normas de conflicto bilaterales y normas que resuelvan cuestiones tales como la remisión a un Estado plurilegislativo, el reenvío, o el orden público, hay que acudir a los convenios vigentes en Colombia. Finalmente, si el sector de la cooperación

${ }^{62}$ Vid. Sentencia de 8 de julio de 2013 de la Sala de Casación de la Corte Suprema de Justicia (Magistrado Ponente Ruth Marina Díaz Rueda), por la que se deniega el exequátur a una sentencia alemana de divorcio, porque la requirente no llega a probar los motivos en los que se fundamenta la decisión alemana para disolver el matrimonio. La decisión, que puede consultarse en la web de la Corte (http://190.24.134.92:8085/Relatoria/csj/index.html), al pronunciarse sobre el alcance de la excepción deja claro que "el fallo extranjero ha de respetar los elementos básicos de la estructura funcional, política, jurídica y social del país, a la Corte le compete examinar si la decisión a validar desconoce o no la legislación reguladora de la ruptura de la disolución de la alianza nupcial, lo cual se impone establecer porque dicho régimen, fundamentalmente alusivo a los efectos derivados del mismo y a las normas que gobiernan su terminación, integran el "orden público" nacional, como lo disponen las normas 18 y siguientes del Código Civil”. En definitiva, parecería aplicar un "orden público” próximo al conflictual", antes que con al sustantivo. Sin embargo, la Sentencia de 6 de junio de 2013 (Ponente Ruth Marina Díaz Rueda) afirma, que “(...), la doctrina ha enseñado que 'no existe inconveniente para un país aplicar leyes extranjeras que, aunque difieran de sus propias leyes, no chocan con los principios básicos de sus instituciones. Sin embargo, cuando una ley extranjera o la sentencia que la aplica, se basan en principios no solo diferentes, sino contrarios a las instituciones fundamentales del país en que aquellas pretenden aplicarse, los jueces del Estado pueden, excepcionalmente, negarse a aplicar la ley o el fallo extranjero que se aparta de esa comunidad de principios", a su vez resaltó, a manera de ilustración, que dichos principios fundamentales se relacionan con la prohibición del ejercicio abusivo de los derechos, la buena fe, la imparcialidad del juez, el respeto al debido proceso, que supone garantizar el derecho de defensa y de contradicción, al igual que el repudio de la prueba ilícita."

${ }^{63}$ Vid., por ejemplo, los Autos de la Sala de Casación de la Corte Suprema de Justicia de 19 de diciembre de 2013 (la resolución de EEUU no se reconoce, entre otros motivos, porque la traducción de la apostilla no se presenta con la legalización de la firma de quien dictó la sentencia); de 25 de noviembre de 2013, dos decisiones: en ambas se deniega el exequátur (primera de sentencia polaca, y segunda de sentencia estadounidense) por falta de constancia de la ejecutoria y traducción no legal); de 21 de octubre de 2013 y de 30 de septiembre de 2013, por el que se deniega el reconocimiento de sendas sentencias españolas (de divorcio, de alimentos y responsabilidad parental) por no presentar constancia de la ejecutoria emitida por el Ministerio de Justicia español. 
internacional de autoridades carece de toda norma estatal, el del reconocimiento y la ejecución de resoluciones extranjeras, que es el que más aplicarían los órganos jurisdiccionales colombianos, resulta también claramente deficiente, en la medida en que parte del análisis de la caduca reciprocidad.

Las evidentes insuficiencias del DIPr colombiano no son paliadas, salvo excepcionalmente, por convenios internacionales que desplacen las soluciones internas. Además, al carácter fragmentario e inconveniente del DIPr de fuente estatal se une la vigencia de convenios bilaterales y multilaterales cuyos criterios de aplicación en ocasiones no aparecen claramente establecidos en el propio instrumento. De hecho, resulta casi excepcional la presencia, en esos instrumentos, de disposiciones que regulen su ámbito espacial, por lo que su aplicabilidad puede resultar incierta, al menos en lo que respecta a los convenios que regulan la competencia judicial internacional y el Derecho aplicable. Si, como todo indica, son convenios inter partes, son escasos los supuestos a los que se aplicarán las normas convencionales, que en ocasiones contienen soluciones más adecuadas a las situaciones privadas internacionales. En cualquier caso, el limitado alcance espacial de los convenios hace que no quepa cuestionar el verdadero alcance de una reforma profunda del DIPr estatal, como ocurre en buena medida en lo que respecta a los sistemas estatales de los Estados miembros de la UE, a la luz de los instrumentos institucionales.

Así las cosas, resulta altamente recomendable que Colombia se dote de un DIPr moderno, que le permita dar una respuesta satisfactoria a las situaciones privadas internacionales que, con cada vez mayor frecuencia, vinculan a este Estado con otros, tanto caribeños como del resto del Mundo. Y a tal fin, no cabe duda de que la Ley Modelo OHADAC constituye una herramienta esencial.

\section{Bibliografía}

Caicedo Castilla, J.J.: Derecho internacional privado, 6aed., Bogotá, Themis, 1967.

Fernández Rozas, J.C.: "El Código de Napoleón y su influencia en América Latina: reflexiones a propósito del Segundo Centenario", El Derecho internacional en tiempos de globalización: libro homenaje a Carlos Febres Pobeda, Universidad de los Andes, Publicaciones del Vicerrectorado Académico, Mérida (Venezuela), 2005, pp. 151-190, esp. pp. 177-178.

Hertel, C.: "Sistemas y familias jurídicos del mundo", Notarius International, 1-2, 2009, pp. 185-200, international.uinl.org/DataBase/2009/Notarius_2009_01_02_hertel_es.pdf.

http://www.notarius-

Londoño Sepúlveda, N.: en "El riesgo en la contratación internacional", en http://www.decconsultores.com/index.php/articulos/185-competenciainternacional

Marín Fuentes, J.L.: "Estado del Derecho Internacional Privado en Colombia y su enseñanza”, disponible en http://asadip.files.wordpress.com/2009/11/ensenanza-del-derechointernacional-privado-en-colombia.pdf).

Oviedo Albán, J.: “La ley aplicable a los contratos internacionales”, Revista Colombiana de Derecho Internacional, núm. 21, 2012, pp. 117-157.

Zuleta Londoño, A.: "Las cláusulas de selección de foro y selección de ley en la contratación internacional: una visión desde el Derecho internacional privado colombiano", Revista de Derecho Privado (Universidad de los Andes) núm. 44, julio-diciembre de 2010, pp. 1-20. 